Journal of BSA, Vol. 18, No. 1 \& 2, 2005

\title{
UPDATE OF NEUROANAESTHESIA IN BANGLADESH
}

\author{
Hasina Begum¹, Iqbal Hossain Chaudhury ${ }^{2}$, AKM Azizul Hoque ${ }^{3}$, UH Shahera Khatun ${ }^{4}$
}

\begin{abstract}
:
In the last 20 years, new drugs and new methods of cerebral monitoring have been introduced, that have affected our choice \& conduct of anaesthesia . Which affects significantly the outcome of neurosurgery. To consider the outcome from neurosurgical anaesthesia, both drugs \& monitors have to be considered.

This is a retrospective study of 2000 patients those who attended in BSMMU from 1985 to 2002 for craniotomy under general anaesthesia. Perioperative mortality (overall) of that period was $5.5 \%$. Perioperative mortality significantly reduced from 1985 to 2002 .
\end{abstract}

In first 6 years $(1985$ - 1990) mortality was $14 \%$; in $2^{\text {nd }} 6$ years $(1991-1996)$ mortality was $6 \%$; in $3^{\text {rd }} 6$ years $(1997-2002)$ mortality was only $2.48 \%$ .At the same time number of patients undergoing surgery greatly increased : In first 6 years ( 1985 $1990)$ it was 225 ; in $2^{\text {nd }} 6$ years $(1991-1996)$ : 557 , in $3^{\text {rd }} 6$ years $(1997-2002): 1169$.

All the above data shows markedly reduced mortality and increased number of surgery indicates tremendous improvement in the field of neuroanaesthesia both in drugs and monitors as well as skillness of neurosurgeons .

To assess changes in outcome, outcome measures need to be defined for neuroanaesthesia. Because the effects of surgery markedly affect neurological or neurophysiological outcome, it can be difficult to distinguish the effects of surgery \& anaesthesia and the effects of new agents.

\section{INTRODUCTION:}

The goal of neuroanaesthesia is to provide a safe anaesthetic for the patient while improving surgical condition in keeping with patient safety.

In the last 20 years new drugs and new methods of cerebral monitoring have been introduced that have affected our choice and conduct of anaesthesia. To consider the outcome from neurosurgical anaesthesia, both drugs \& monitors as well as skilled manpower have to be considered.

As the effects of surgery markedly affect neurological or neuropsychological outcome, it can be very difficult to distinguish the effects of surgery \& anaesthesia. But gradual increase in availability of sophisticated monitoring techniques $\&$ improved operating condition under anaesthesia have allowed increasingly difficult procedures to be performed on patients previously deemed inoperable.

In 1980's IPGMR and DMCH (Dhaka Medical College Hospital) were the only two established centers for neurosurgical operative procedures, where most of the cases were emergency one. But now a days all medical college hospitals \& some private clinics $\&$ hospitals are doing the job very efficiently.

This paper examines the effects of agents, techniques \& monitoring facility for neurosurgical outcome in Bangladesh.

\section{METHODS \& MATERIALS:}

It was a retrospective study of 2000 patients who attended in BSMMU from 1985 to 2002 for craniotomy under general anaesthesia. The patients were divided in three groups: Group A: patients were admitted \& operated in year 1985 1990 ( $1^{\text {st }} 6$ years); Group B: patients were admitted \& operated in year $1991-1996$ ( $2^{\text {nd }} 6$ years $)$; Group C: patients were admitted \& operated in year 1997 -2002 ( $3^{\text {rd }} 6$ years). In both groups total number of mortality were assessed, in addition to that the mortality also assessed in post. fossa operations \& operations other than post. fossa.

The data were compiled and analyzed for statistical significance by ANOVA test or unpaired t test as appropriate. $\mathrm{P}$ value $<0.05$ was considered significant.

1. Junior Consultant, Anaesthesia, Analgesia \& ICU, DMCH

2. Assistant Professor, Anaesthesia, Analgesia \& ICU, BSMMU

3. Associate Proessor, Anaesthesia, Analgesia \& ICU, DMCH

4. Professor, Anaesthesia, Analgesia \& ICU, DMCH 
RESULTS:

Table : 1

Overall mortality (1985-2002)

\begin{tabular}{lll}
\hline Total cases & $:$ & 2000 \\
Total operations & $:$ & $1941(97.05 \%)$ \\
Un-operated cases & $:$ & $59(2.95 \%)$ \\
Peri-operative mortality & $:$ & $111(5.71 \%)$ \\
\hline
\end{tabular}

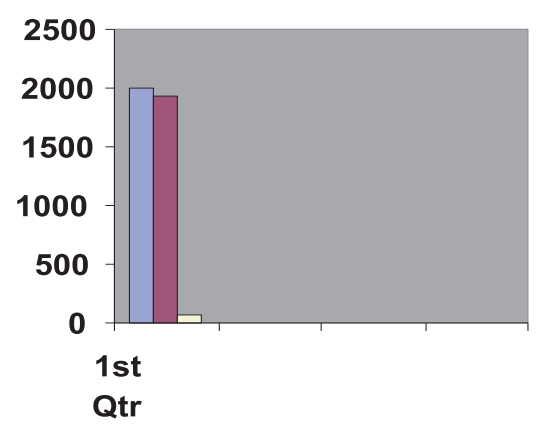

Total cases

Total operations

$\square$ Unoperable cases

Table-II

Peri-operative mortality (1985-2002) in IPGMR

\begin{tabular}{llccc}
\hline Sl. no & Diagnosis & Total oper. & Total death & Percentage \\
\hline 1. & Astrocytomas & 754 & 22 & $3.05 \%$ \\
2. & Meningiomas & 407 & 15 & $3.93 \%$ \\
3. & Pituitary tumors & 235 & 19 & $8.51 \%$ \\
4. & Craniopharyngiomas & 172 & 15 & $9.00 \%$ \\
5. & Acoustic Neuromas & 158 & 16 & $12.03 \%$ \\
6. & Medulloblastoma & 119 & 12 & $11.76 \%$ \\
7. & Brain abscess & 114 & 3 & $3.51 \%$ \\
8. & Meningeal Sarcomas & 19 & 3 & $15.79 \%$ \\
9. & Arachnoid Cyst & 13 & 1 & $8.00 \%$ \\
10. & Colloid Cyst & 11 & 4 & $36.36 \%$ \\
11. & Fibrosarcoma & 1 & 1 & $10.00 \%$ \\
\hline & Total & 2000 & 111 & $5.71 \%$ \\
\hline
\end{tabular}

Table - III

Operative mortality in GroupA, GroupB \& GroupC (1985-2002)

\begin{tabular}{llccc}
\hline Sl.no. & & Group A & GroupB & Gruop C \\
& & $1985-1990$ & $1991-1996$ & $1997-2002$ \\
\hline 1. & Total operations & 225 & 577 & 1169 \\
2. & Total operative deaths & $33(14.66 \%)$ & $36(6.0 \%)$ & $29(2.48 \%)$ \\
3. & Post. fossa mortality & 15 & 8 & 6 \\
4. & Mortality other than post. fossa & 18 & 28 & 23 \\
5. & \% of post. fossa operative mortality & $39.47 \%$ & $10.5 \%$ & $3.0 \%$ \\
6. & \% of mortality other than post. fossa & $9.63 \%$ & $5.8 \%$ & $2.33 \%$ \\
\hline
\end{tabular}


Table-IV

Total operations in Group A, Group B \& Group C

\begin{tabular}{lcc}
\hline Groups & Total operations & ANOVA \\
\hline Group A (1985-1990) & 225 & $\mathrm{P}<0.01$ \\
Group B (1991-1996) & 577 & \\
Group C (1997-2002) & 1169 & \\
\hline
\end{tabular}

$\mathrm{S}=$ Significant.

NS $=$ Not significant.

HS = Highly significant .

Table-V

Total operative deaths in Group A, Group B \& Group C

\begin{tabular}{lcc}
\hline Groups & $\begin{array}{c}\text { Total operative } \\
\text { deaths }\end{array}$ & ANOVA \\
\hline Group A (1985-1990) & 33 & P $>0.05 N S$ \\
Group B (1991-1996) & 36 & \\
Group C (1997-2002) & 29 & \\
\hline
\end{tabular}

Table-VI

Total Post. fossa operative deaths in Group A, Group B \& Group C

\begin{tabular}{lcc}
\hline Groups & $\begin{array}{c}\text { Total post. fossa } \\
\text { operative deaths }\end{array}$ & ANOVA \\
\hline Group A (1985-1990) & 15 & P $>0.05$ \\
Group B (1991-1996) & 08 & NS \\
Group C (1997-2002) & 06 & \\
\hline
\end{tabular}

Table-VII

Percentage of mortality in Group A, Group B \& Group C

\begin{tabular}{lcc}
\hline Groups & $\begin{array}{c}\text { Percentage of } \\
\text { mortality }\end{array}$ & ANOVA \\
\hline Group A (1985-1990) & $14.66 \%$ & $\mathrm{P}<0.05 \mathrm{~S}$ \\
Group B (1991-1996) & $6.0 \%$ & \\
Group C (1997-2002) & $2.48 \%$ & \\
\hline
\end{tabular}

$\mathrm{S}=$ Significant.

NS $=$ Not significant.

HS = Highly significant .

\section{DISCUSSION:}

Apart from a conventional anaesthetic technique which plays meticulous attention to detail the essential factors in neuroanaesthesia are the maintenance of cerebral perfusion pressure and the facilitation of surgical access by minimizing blood loss and preventing increases in central nervous tissue volume and oedema ${ }^{1}$.

The data shows tremendous improvement of outcome of neurosurgical patients from 1985 to 2002. Though the data is taken from IPGMR, it might be the overall reflection of neurosurgical outcome of Bangladesh.

Introduction of new sophisticated drugs gives remarkable improvement in the field of neuroanaesthesia. The effects of anaesthetic agents on cerebral metabolism, blood flow, cerebrospinal fluid(CSF) dyanamics and intracranial volume \& pressure are often profound. ${ }^{2}$ Peroperative cerebral ischaemia markedly affects postoperative outcome. In 1985 most of the patients were anaesthetised with Barbiturates, halothane, tubocurarine / gallamine \& suxamethonium. All these drugs markedly affects cerebral perfusion \& metabolism.

\section{Introduction of new drugs are :}

1. Intravenous: Propofol.

2. Volatile anaesthetic agents: Isoflurane.

3. Fentanyl, Remifentanyl.

4. New NMB agents like: Vecuronium, pipecuronium etc.

In vitro, propofol directly dilates cerebral vessels, ${ }^{3}$ whereas in vivo it causes cerebral vesoconstriction, presumably by reducing cerebral metabolic rate $\&$ thus cerebral blood flow ${ }^{4}$. However cerebral blood flow decreases more markedly than cerebral metabolism \& some suggests that propofol causes direct cerebral vasoconstriction. During propofol anaesthesia, cerebral vessels remain reactive to changes in $\mathrm{PaCO} 2$ \& changes in cerebral perfusion pressure, but the responses are less. ${ }^{5}$

In general, volatile anaesthetic agents dilate the cerebral vessels. ${ }^{6}$ Their overall effect on cerebral blood flow depends on the balance between this direct vasodilatation \& the indirect effect of decreased metabolism \& flow-metabolism coupling leading to vasoconstriction. 
Although the effects of anaesthetics are related to the effects on cerebral blood flow, in fact cerebral blood volume is a critical factor affecting intracranial pressure \& brain volume. In summary, Isoflurane is as suitable as propofol for neuroanaesthesia in a concentration below 1.5 MAC. However, the indication for some small direct vasodilatation in comparison to the direct vasoconstriction of propofol may offer savoflurane some potential advantages. ${ }^{7}$

Semi-synthetic opiates have in general, only minor or transitory effects on ICP \& on cerebral hemodynamics. However, in patients with lesions such as head trauma or cerebral tumors, opiates can increase ICP during induction of anaesthesia or sedation in the intensive care unit ${ }^{8}$, related to an increase in CBF. In a study Remifentanil was compared with fentanyl in a randomized, doubleblinded, prospective trial, for elective supratentorial craniotomy for space occupying lesions ${ }^{9}$. Remifentanil was a reasonable alternative to fentanyl, with similar adverse events, hemodynamic profiles \& median recovery times ${ }^{10}$.

For years, controlled or induced hypotension has been the cornerstone of the anaesthetic management during cerebrovascular surgery. However, more and more data indicated that arterial hypotension could cause cerebral ischemia. Although the safe limits of arterial hypotension have never been determined, it seems advisable to maintain normotension during neurosurgical procedures to avoid controlled or induced hypotension, which could be detrimental. Reducing arterial $\mathrm{CO}_{2}$-tension is one of the most efficient ways to decrease cerebral blood flow, and hence intracranial pressure. However, the cerebral vasoconstriction caused by hyperventilation may be so intense that the limits of cerebral ischemia can be reached. This was shown in severe head injury where prolonged hyperventilation increased the incidence of cerebral ischemia, the same may be true for neurosurgical anaesthesia. Therefore, end-tidal $\mathrm{CO}_{2}$-tension should be monitored, as well as arterial $\mathrm{CO}_{2}$-tension, to maintain normocapnia during neurosurgical procedures.
Improvement of OT environment, patient position \& close monitoring of the patient both clinical \& instrumental like :

- Continuous monitoring of ECG.

- BP monitoring every 5 mins or earlier.

- Monitoring of $\mathrm{SP}_{2}$.

- Monitoring of $\mathrm{ETCO}_{2}$.

- Central Venous pressure (CVP) monitoring.[ selected cases ].

- IBP measurement [selected cases].

- Temperature monitoring.

- Availability of post-operative controlled ventilation.

In 1980 there was no monitors except clinical. In 1985 only pulse oximeter was introduced. After that all monitors were introduced day by day and presence of qualified anaesthesia personnel gives very good outcome.

But specialized monitoring device of CNS for measurement of adequacy of CBF, ICP, cerebral metabolism are even now not available in Bangladesh.

If we give a look to skilled manpower: In 1980 there was no Fellow (FCPS) in anaesthesia. The $1^{\text {st }}$ FCPS in anaesthesia in Bangladesh passed in 1983, where as in 2004 the number of Fellows are 65. Other postgraduates like MD, Diploma (DA), member of BCPS (MCPS) all increased in the same ratio[statistics from $\mathrm{BCPS}$.

\section{CONCLUSION:}

Meticulous use of all drugs, monitors as well as techniques of anaesthesia like hyperventilation, patients position, post-operative controlled ventilation and last of all skilled personnel are responsible for present position in case of neuroanaesthesia.

Introduction of monitoring device for measuring ICP, CBF, ABG \& other neurological parameter. Specialized neuro ICU \& neuro-postoperative care will give more effective $\&$ fruitful results.

\section{REFERENCES:}

1. A.R.Aitkenhead; Textbook of Anaesthesia; $3^{\text {rd }}$ ed; Neurosurgical anaesthesia; page 603. 
2. Morgan,Mikhali,Murray; clinical Anaesthesiology; $3^{\text {rd }}$ ed; Neurophysiology and anaesthesia; page 552 .

3. Gelb AW, Zhang C, Hamilton JT. Anaesth Analg 1996; 83: 472-6

4. Nakamura K, Hatano Y, Hirakata $\mathrm{H}$ et al. Br J Anaesth 1992; 68: 193-7

5. Fox J, Gelb AW, Enns J et al. Anaesthesiology; 1992; 77:453-6

6. Ornstein E, Young WL, Fleischer LH et al. Anaesthesiology; 1993; 79: 498-502
7. Cathy S. DE DEYNE ; Do new anaesthetic techniques make a difference to outcome?; ESA Refresher Courses ; [file://C: \ Documents\% 20and\%20Settings $\backslash$ Sakib $\backslash$ My\%20Documents \New\% 20Folder $\backslash 7 \mathrm{rc} . \mathrm{h} . .$.

8. Albanese J, Durbec O, Viviand X et al. Anaesthesiology; 1993; 79: 493-7

9. Guy J, Hindman BJ, Baker KZ et al. Anaesthesiology; 1997; 86: 514-524

10. Balakrishnan G, Raudzens P, Samra S et al. Anaesth Analg 2000; 91: 163-9.. 